Article

\title{
Behavior of Concrete under the Addition of High Volume of Polyolefin Macro Fiber and Fly Ash
}

\author{
Suman Kumar Adhikary * and Zymantas Rudzionis \\ Faculty of Civil Engineering and Architecture, Kaunas University of Technology, Kaunas LT-44249, Lithuania; \\ zymantas.rudzionis@ktu.lt \\ * Correspondence: sumankradk9s@gmail.com; Tel.: +91-820-724-6551
}

Received: 26 April 2018; Accepted: 5 June 2018; Published: 7 June 2018

check for updates

\begin{abstract}
This paper deals with behavior of concrete's compressive and bending strengths with the addition of high amount of polyolefin macro fibers. Polyolefin fiber is used to increase the bending strength and compressive strength, these experiments are done to investigate the cracking behavior and found the bending strength and compressive strength of polyolefin fiber reinforced concrete. Normally, concrete is mixed with various amount of fiber, but in this experiment five different specimens were prepared, S-1 is without fiber; S-2, homogeneous mixing of fiber volume of $10 \mathrm{~kg} / \mathrm{m}^{3}$; S-3, homogeneous mixing of fiber volume of $25 \mathrm{~kg} / \mathrm{m}^{3} ; \mathrm{S}-4$, homogeneous mixing of fiber volume of $35 \mathrm{~kg} / \mathrm{m}^{3}$; and S-5, which contains $25 \mathrm{~kg} / \mathrm{m}^{3}$ fiber mixed by hand in three different layers. A small amount of fly ash (18.18\% of cement mass) is also mixed in the concrete specimens for better results. Concrete specimens were tested on 7th day and 28th day of the curing process. Water absorption capacity and compressive strength tests were done in the dry state and wet state to find the strength difference. More than $50 \%$ of flexural strength was gained on the 28th day of the destructive test. Post-cracking behavior was observed on the 28th day of the test, the specimens with fiber content were found to take load after cracking and hold more load to failure.
\end{abstract}

Keywords: polyolefin fiber; fiber reinforced concrete; flexural strength

\section{Introduction}

Concrete is most used material in the construction sector because of its various properties like strength, durability, and cost effectiveness, etc. In general, concrete is highly efficient and durable material, but sometimes because of construction, needs some admixtures to increase its performance. In past few years, fiber-reinforced concrete has gained considerable attention in the field of civil engineering infrastructures like bridges, tunnels, airports, slabs, shelters, and pavements, etc. Due to poor construction, environmental exposure leads to degradation, micro cracks, and corrosion. The presence of chloride ions, water, and carbon dioxide in the concrete increases the chance of steel corrosion. To overcome these types of problems, fibers have become integral part of construction application [1]. Nowadays, the uses of fibers in the concrete mixture is a well-known concept. Fibers in the concrete are used to increase the ductility and toughness. Formations of micro and macro-crack are the main causes for the destruction and collapse of concrete structure [2-4]. Thermal and humidity changes, in the cement paste leads to formations of micro-cracks, that concentrates on coarse aggregate surfaces. And due to more loading and environmental effects more micro-cracks form in the concrete. Applying various kind of fibers in the concrete improves the crack formation factor, concrete toughness, energy absorptions and reduce the chances of structural failure specially in earthquake zones [5]. Various types of fibers are tested and are being used in the construction sector like carbon fiber, steel fiber, glass fiber, plastic fiber, and nylon fibers, etc. [6]. In 2006, the European Committee for Standardization (CEN) approved the European Standards EN 14889-1 
and EN 14889-2 [7], these standards classify the types of fibers which can be used in the concrete mixture. This classification divides into two groups, as steel fibers and polymer fibers. Nowadays, polyolefin fibers have become the best alternative to steel and all other fibers [8] because of various benefits. Steel fibers have good impact on strength properties, but in few cases, it becomes the reason for corrosion and loses its potential properties with the passage of time. Also, polyolefin fibers impact/strength ratio and toughness factor are higher than the steel fibers [9]. Polyolefin fibers are synthetic hydrocarbon polymers, which are produced by polymerizing monomer units of propylene molecules into very long polymer molecules. Polyolefin fibers are not affected by salt water and do not cause corrosion and alkali attack. Polyolefin fibers have the ability to resist alkaline environments without affecting its properties [10]. Further, polyolefin fibers are also hydrophobic, which means that it will not absorb water and does not affect concrete properties [11]. It is low cost material compared to other fibers, light weight, and easy to handle. Polyolefin fibers do not react with concrete chemically and it gains bonding by its mechanical interaction. Polyolefin fibers can be designed in any cross-sectional shapes with a variety of surface finishes to increase the bonding properties. It has been observed that using a proper amount of polyolefin fiber, cracking behavior can be reduced almost up to $100 \%$ [12]. Saghi and Delberi found that the increase of fibers in concrete from $2 \%$ to $3 \%$ decreases the crack surface of polyolefin shrinkage up to $98 \%$ [13]. Pujadas found that using plastic macrofibre content of $9 \mathrm{~kg} / \mathrm{m}^{3}$ volume in flat suspended slab has higher stress bearing capacity and good ductile behavior with great redistribute forces keeping a high load level after cracking [14]. Anyhow, polyolefin fibers have various advantages, but still, steel fibers are preferably used over macro-synthetic fibers. One of the major problems of polyolefin fibers is creep. The creep behavior of synthetic fibers is a complex phenomenon, which depends not only on the stress and temperature, but also on intrinsic material properties, such as the crystallinity and the molecular orientation, as well as other external parameters such UV and moisture [15]. Pujadas found in his experiments that the creep rate of plastic fiber was higher than the value of steel fibers. Use of macro-polyolefin fibers as reinforcement should not be desirable as long as the effects of creep are considered in the design. And the design criteria will define the scope of applications of polyolefin macro-fiber as reinforcements and are needed to meet the ULS (ultimate limit state) and SLS (serviceability limit state) requirements [16]. In this paper we concentrated on the behavior of concrete under the addition of a high volume of polyolefin fibers. How the flexural and compressive strength changes with the addition of polyolefin fibers. And to find out the reason for using high volume of fibers in the concrete and to check if it is worthy enough to add high volumes of fibers in concrete.

\section{Used Materials and Proportion of Mixing}

Ordinary Portland cement satisfying EN 197-1:2011 of grade CM I 42.5R (Rocket cement M-600, AB Cementa, Stockholm, Sweden) and local sand (fine aggregate) were used in this study. Small amounts of fly ash were used as an admixture. A Sika Viscocrete-D187 named polycarboxylate-based superplasticizer with 28\% solid content satisfying EN 934-2:2009 was added to the concrete mixture. Rough surface designed macro size polyolefin straight fibers were employed in various proportions. The specifications of the fiber can be seen in Figure 1.

To get the results for the different fiber content concretes, five different types of concrete samples were prepared with various amount of fiber content. In all the concrete specimens, the quantity of cement, sand, water/cement ratio, fly ash, and superplasticizer were same; only polyolefin macro fiber quantity and mixing style were changed. The mixing proportion of all samples were shown in Table 1.

The five-samples were named S-1, S-2, S-3, S-4, and S-5. Sample S- 1 was prepared without any fiber content; samples S-2, S-3, and S-4 contained different amounts of fibers of $10 \mathrm{~kg} / \mathrm{m}^{3}, 25 \mathrm{~kg} / \mathrm{m}^{3}$, and $35 \mathrm{~kg} / \mathrm{m}^{3}$, respectively, and fibers were mixed homogeneously. The last sample, S-5, was prepared with $25 \mathrm{~kg} / \mathrm{m}^{3}$ volume of polyolefin fibers, and the fibers were employed in the concrete using three different layers by hand with horizontal orientations. 


\begin{tabular}{l} 
Material: Polyolefin \\
Length: $50 \mathrm{~mm},+/-5 \%$ \\
Diam eter: $500 \mu \mathrm{m}$ \\
Elasticity Modulus: $>11 \mathrm{GPa}$ \\
Tensile Strength: $\approx 590 \mathrm{~N} / \mathrm{mm}^{2}$ \\
Softening Point: $\approx 150^{\circ} \mathrm{C}$ \\
Bulk Density: 0.91 \\
\hline
\end{tabular}
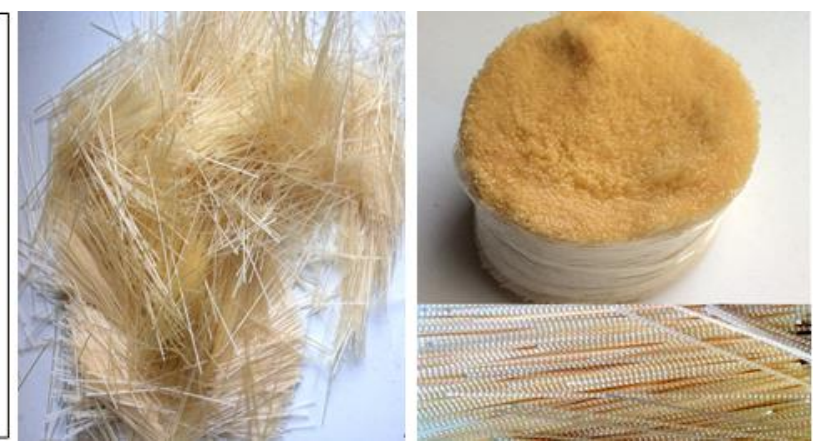

Figure 1. Properties of polyolefin macro fibers.

Table 1. Mixing proportion of concrete.

\begin{tabular}{|c|c|c|}
\hline Materials Used for Concrete Mixture Preparation & \multicolumn{2}{|c|}{ Quantity of the Materials for $1 \mathrm{~m}^{3}$ of Concrete } \\
\hline Fine aggregate & \multicolumn{2}{|c|}{$1640 \mathrm{~kg}$} \\
\hline Cement & \multicolumn{2}{|c|}{$506 \mathrm{~kg}$} \\
\hline Water & \multicolumn{2}{|c|}{$170(\mathrm{~W} / \mathrm{C}$ ratio 0.335$)$} \\
\hline Fly ash & \multicolumn{2}{|c|}{$92 \mathrm{~kg}(18.18 \%$ of cement mass) } \\
\hline Super plasticizer & \multicolumn{2}{|c|}{$7.6 \mathrm{~kg}(1.5 \%$ mass of cement $)$} \\
\hline \multirow{5}{*}{ Polyolefin fibers } & S-1 & No fiber \\
\hline & S-2 & $10 \mathrm{~kg}$ \\
\hline & S-3 & $25 \mathrm{~kg}$ \\
\hline & S-4 & $35 \mathrm{~kg}$ \\
\hline & S-5 & $25 \mathrm{~kg}$ \\
\hline
\end{tabular}

To prepare the fresh concrete samples, all the procedures were done very carefully. After the making of each type of concrete samples, the slump test was carried out according to GOST (23789-85) standard. Circular cylindrical shape equipment, namely a Sutard viscozimeter, was used to carry out the slump test. The equipment had an external diameter of $57 \mathrm{~mm}$, internal diameter of $50 \mathrm{~mm}$, and a height of $99.5 \mathrm{~mm}$. The influence of the fibers on the slump values are shown below. The slump value was decreasing by the quantity of fibers. After the slump test, each type of sample was molded to the size of $16.04 \mathrm{~cm} \times 4.0 \mathrm{~cm} \times 4.0 \mathrm{~cm}$ for the destructive tests. All the specimens were kept in a climatic chamber for $24 \mathrm{~h}$. After the process, the specimens were taken out of the mold and immersed in water and kept for 6 and 27 days in climatic chamber respectively. Slump value of concrete samples and concrete production procedures are shown in Figure 2.

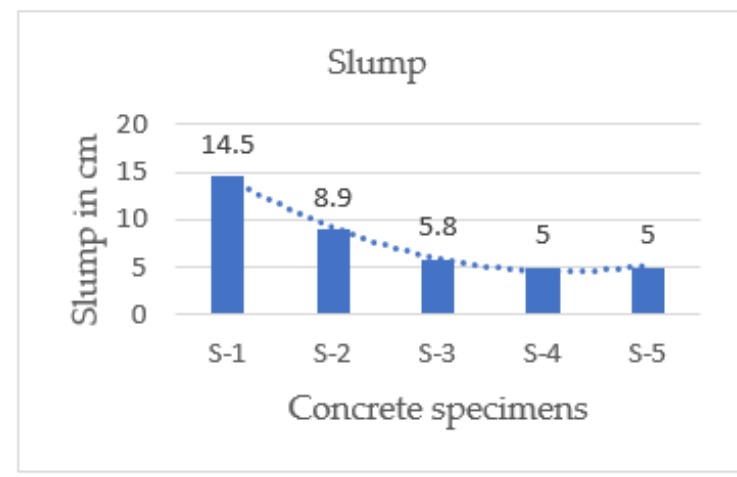

\begin{tabular}{|l|}
\hline - Calculate mixing proportions \\
- Mixed and prepare each type of fresh \\
concrete \\
\hline -Slump test \\
\hline - Pour the concrete in mold \\
\hline $\begin{array}{l}\text { - Put the concrete samples for } 24 \text { hours in } \\
\text { climatic chamber }\end{array}$ \\
\hline - Demolded concrete and kept in water \\
\hline - Specimens tested on 7 days and 28 days \\
\hline
\end{tabular}

Figure 2. Slump value of concrete specimens and procedure of concrete production and tests. 
After 7 and 28 days, all the concrete specimens were taken out to calculate their water absorption capacity and to conduct strength tests. The masses of each type of concrete specimens were calculated in wet stage. Afterwards, yet another sample of each type of concrete was kept in an oven to calculate the mass in dry state. It was observed that on the 7th and 28th day, the rate of absorption was higher for S-5. Figure 3 shows the variations of water absorption.

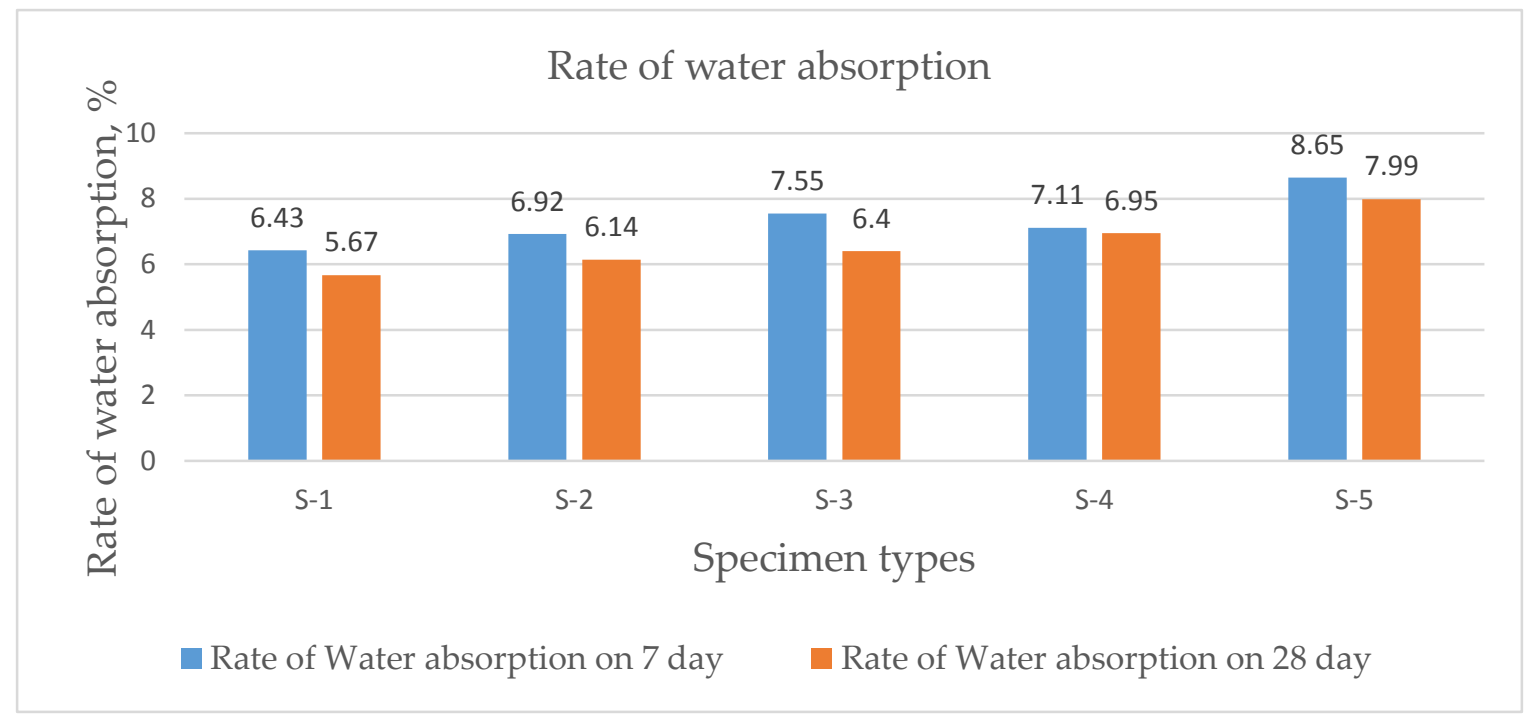

Figure 3. Water absorption of concrete samples on 7 and 28 day.

\section{Mechanical Properties Evaluation}

Compressive and flexural strength tests were done at 7 and 28 days, using three specimens of each type and mean values were taken as the results. Compressive and flexural tests were done according to EN 196-1:2016 and additionally, a high accuracy electronic extensometer was used for the determination of deformations during flexural tests. Water cement ratio is an important factor, variation of water/cement ratio causes high strength difference. It has been observed that less water cement ratio provides higher strength [17-19]. In this experiment, we used a 0.335 water/cement ratio, so higher strength was expected. On the 7th days and 28th days, compressive strength was tested in both wet and dry states to check the variation of strength. Compressive strength tests in wet state were conducted in the morning of 7 th and 28th day of testing. And dry state testing was conducted in the afternoon of the same day. The samples were dried in an oven at a temperature of $100^{\circ} \mathrm{C}$. It was observed that compressive strength of samples in dry state on the 7th day were almost similar to the compressive strength of samples in wet state on the 28 th day of testing. According to the theory of concrete science, it was expected to achieve higher strength in the dry state. Compressive strength of the concrete samples was decreasing with the bigger quantities of fibers. On the 7th day, the without-fiber-content sample, S-2, had the highest compressive strength in the wet stage. Whereas S-5 showed the lowest value of compressive strength. According to theory of concrete science, concrete has higher strengths in the dry stage. In this experiment in the wet stage, sample S-2 achieved higher strength in the early stage (on 7th day) than any of the other samples. While sample S-1 achieved higher strength on the 28th day compressive test than any of the other concrete samples. And the compressive strength of the concrete samples was decreasing with the quantity of fibers. Higher quantity of fibers in the concrete affected the strength properties, it was observed from these experiments that sample S-4 achieved very low compressive strength because of its higher fiber concentration. Sample S-3 and S-5 had the same fiber concentration, but because of fiber orientation, we achieved different compressive strength values. The variation of compressive strength of all the samples are shown in Figures 4 and 5 . 


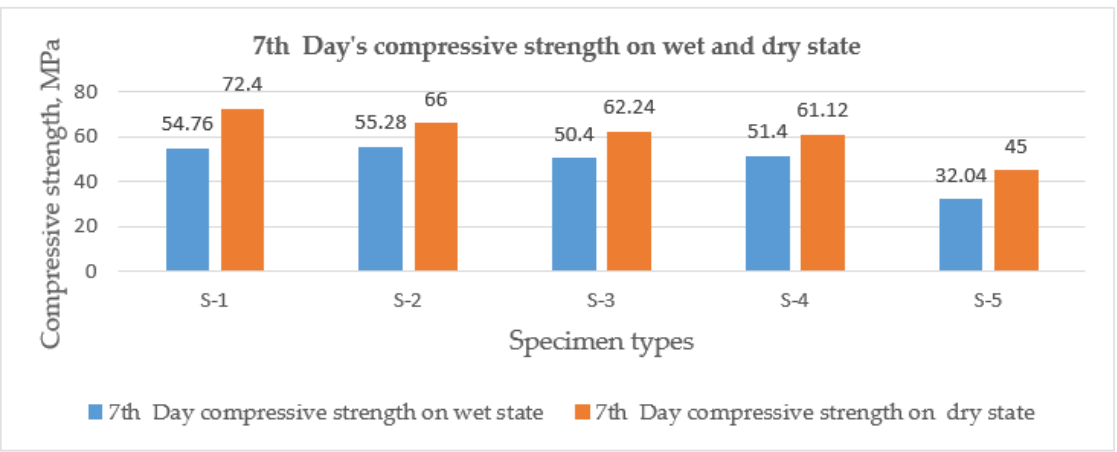

Figure 4. 7th day compressive strength of concrete samples on wet and dry state.

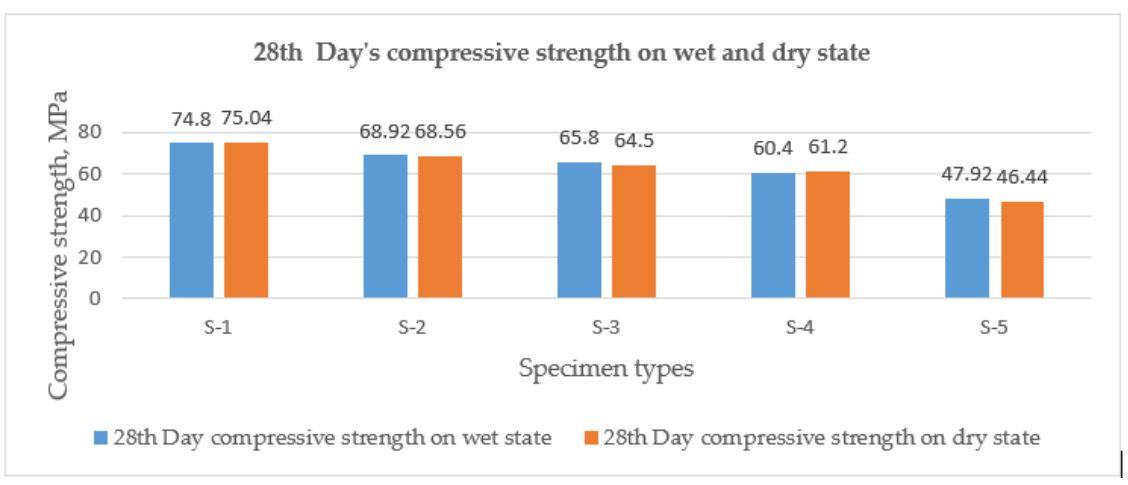

Figure 5. 28th day compressive strength of concrete samples on wet and dry state.

The flexural strength of the concrete samples were tested using the three-point flexural test method. The testing machine was connected through a computer and high accuracy electronic extensometer was used to get accurate data for the deformations. All the specimens were tested until all of them had separated into two parts. S-1 separated into two parts under a certain load. But the other specimens, S-2, S-3, S-4, and S-5, remained in single parts because of the high fiber content. Although the concrete broke, the fiber held the concrete together. On 7th day flexural strength test, it was observed that the bending strength of concrete was increasing with the quantity of fibers and after certain quantity, it started decreasing. In the early stage, sample S-3 achieved higher bending strength. While on 28th day bending test, sample S-2 achieved higher bending strength than any of the other samples, and later it started decreasing with the quantity of fibers. The variation of bending strength of all the samples are shown in Figures 6 and 7.

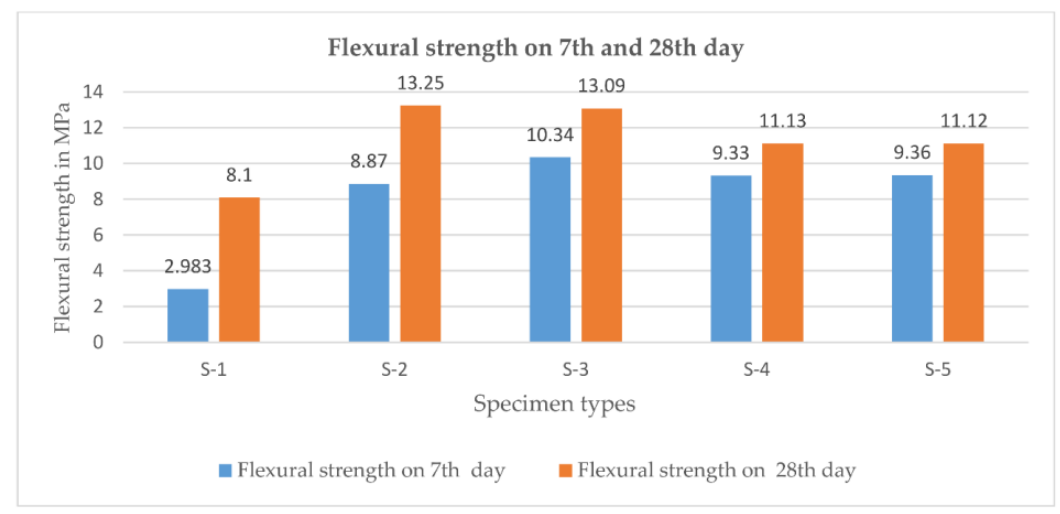

Figure 6. Flexural strength of concrete samples after 7 and 28 day of hardening. 


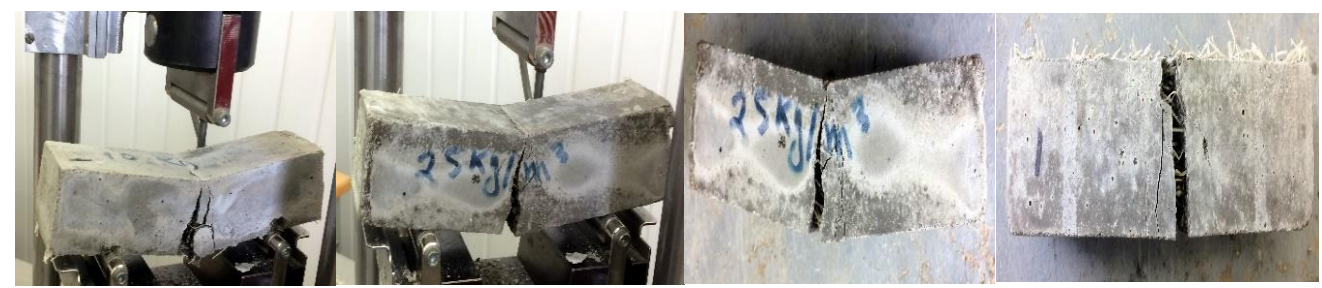

Figure 7. Concrete samples after final bending result.

\section{Cracking Behavior of Concrete Samples}

The cracking behavior of concrete is an important factor of concrete structures. Fibers generally have post cracking properties, which depend upon types of fiber and its classes. In this study, we used polyolefin fibers, which had good results in terms of post cracking properties. Concrete sample S- 1 on the 28th day had 8.1 MPa bending strength. This sample did not have any fiber content, which was why only a single crack was found and that led to the breaking of the concrete sample under a certain load. But the fiber content samples, S-2, S-3, showed their first cracks at near about $8.0 \mathrm{MPa}$ bending strength. Similar phenomena were observed in S- 4 and S-5 under the stress of +6.0 MPa. S- 2 on 28th day, with the first crack (minor crack) occurring near about $8.0 \mathrm{MPa}$ and the second crack on near 9.0 MPa bending strength, with the concrete sample failing with a major crack on $13.25 \mathrm{MPa}$. Where S-1 failed at the first crack at $8.1 \mathrm{MPa}$ bending strength and separated into two parts. However, all the fiber content samples were not fully separated because of high fiber concentration. Although there was breaking, the fibers held the concrete and resisted to separation into two parts, as shown in the Figure 7. Similar phenomenon were observed for other concretes samples with different bending strength values. The following Figures $8-12$ show the stress deflection curve. Post-cracking behavior of fiber reinforced concrete of was not measured in this study, in future studies it will be evaluated.

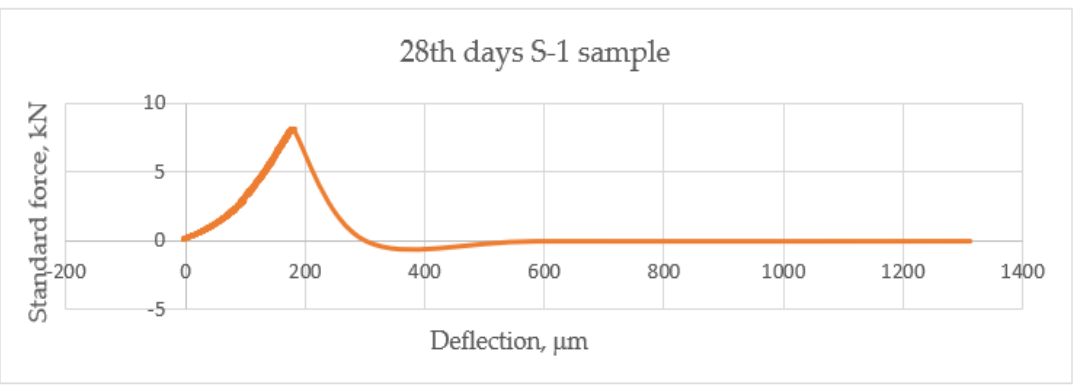

Figure 8. 28th day S-1 sample's crack behavior.
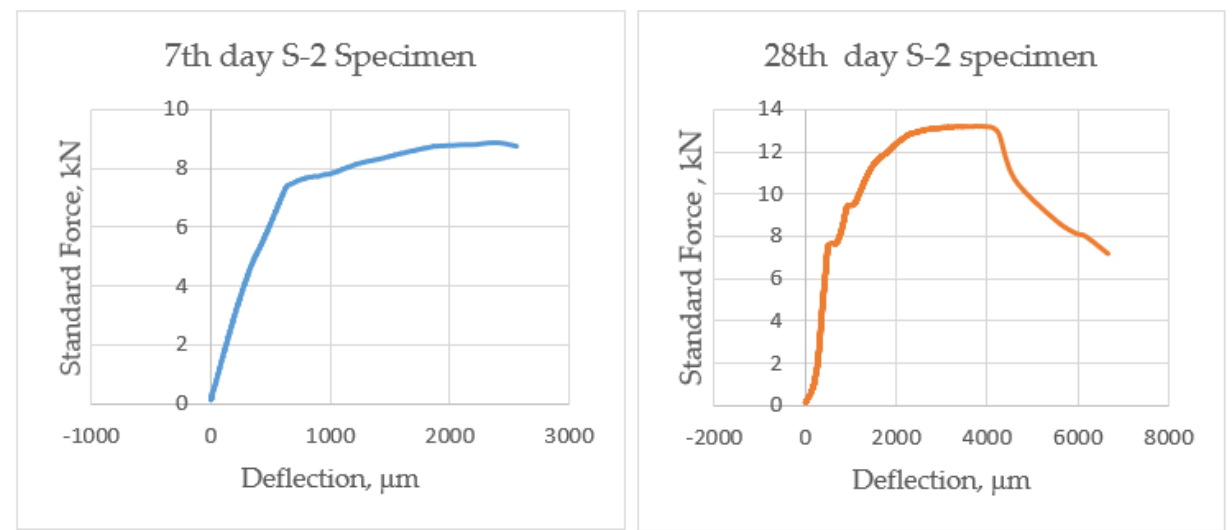

Figure 9. Crack behavior of sample S-2 after 7 and 28 day of hardening. 

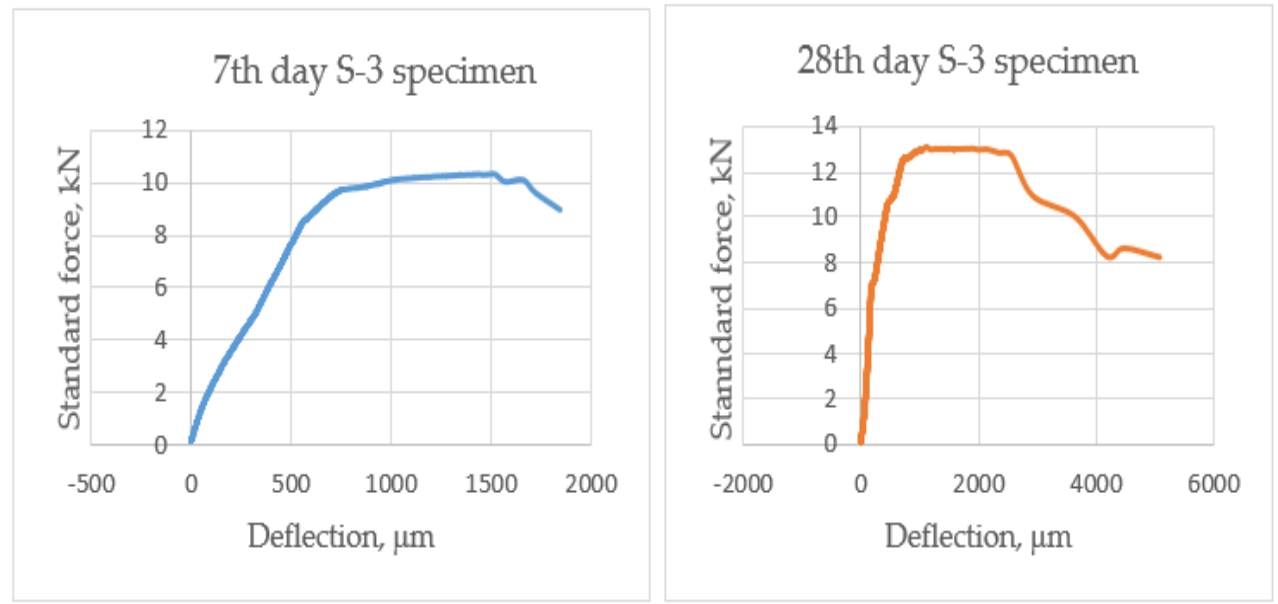

Figure 10. Crack behavior of sample S-3 after 7 and 28 day of hardening.
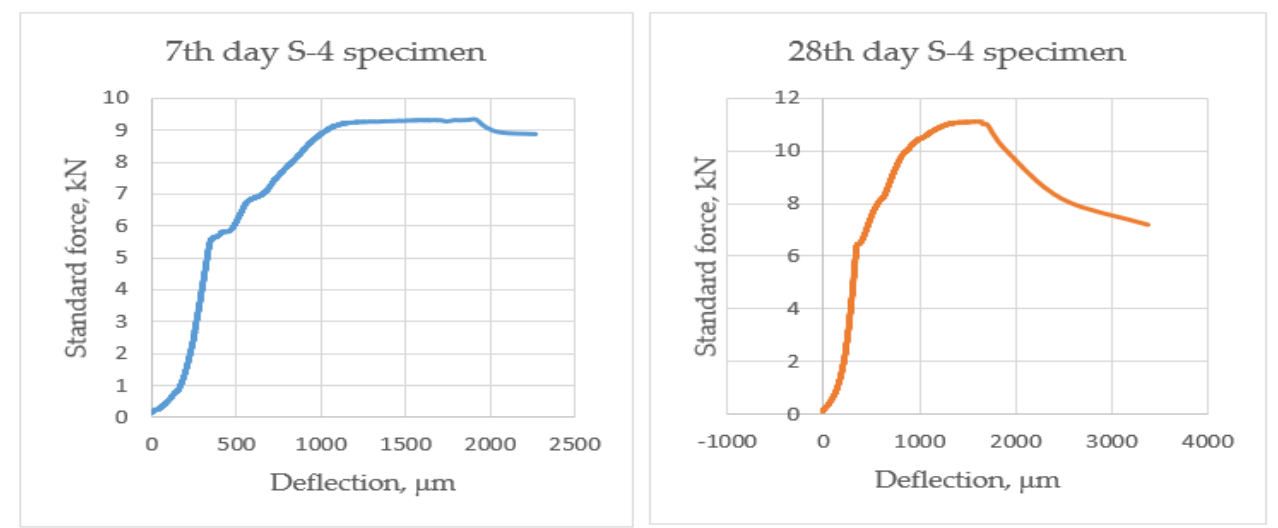

Figure 11. Crack behavior of sample S-4 after 7 and 28 day of hardening.
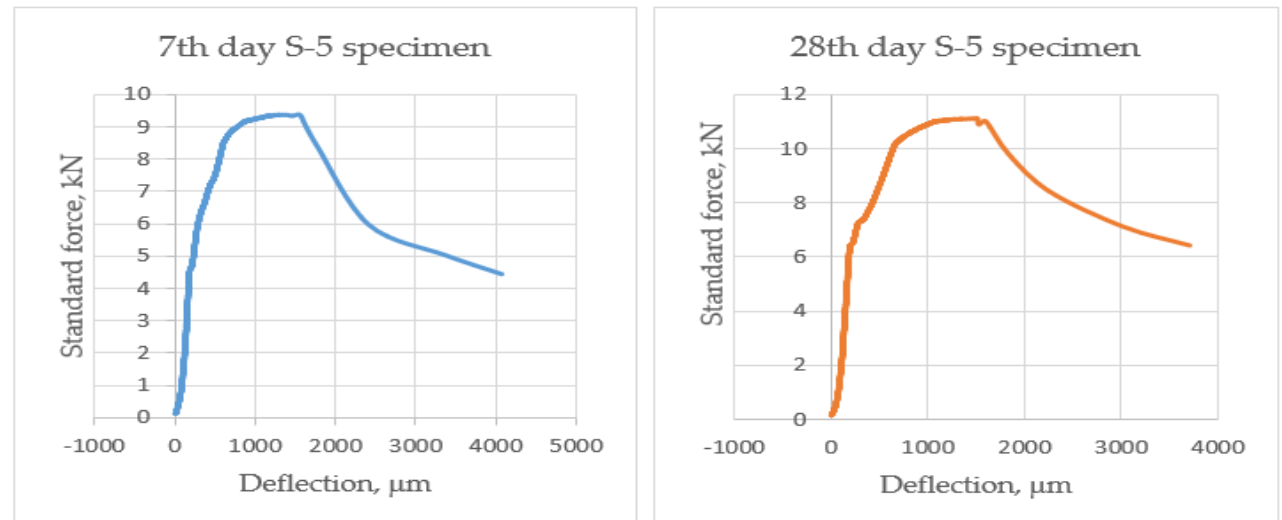

Figure 12. Crack behavior of sample S-5 after 7 and 28 day of hardening.

\section{Fiber Concentration of Concrete}

For fibers of each type of concrete specimens, the average concentration in the cross section were calculated. The number of fibers in each cross section are shown below in Table 2. For S-3 and S-5, the fiber quantity in the mixtures was $25 \mathrm{~kg} / \mathrm{m}^{3}$. Sample S- 5 had a higher number of fibers than S-3 because of fiber orientation differences. Sample S-2, S-3, and S-4 were mixed homogeneously, whereas 
the fibers in S-5 were spread by hand in three different layers. Figure 13 shows the cross section of the concrete samples.

Table 2. Average no of fibers in cross-section of each type samples.

\begin{tabular}{cccccc}
\hline Type of Specimen & S-1 & S-2 & S-3 & S-4 & S-5 \\
\hline No of fibers in cross-section & 0 & 38 & 75 & 102 & 95 \\
\hline
\end{tabular}
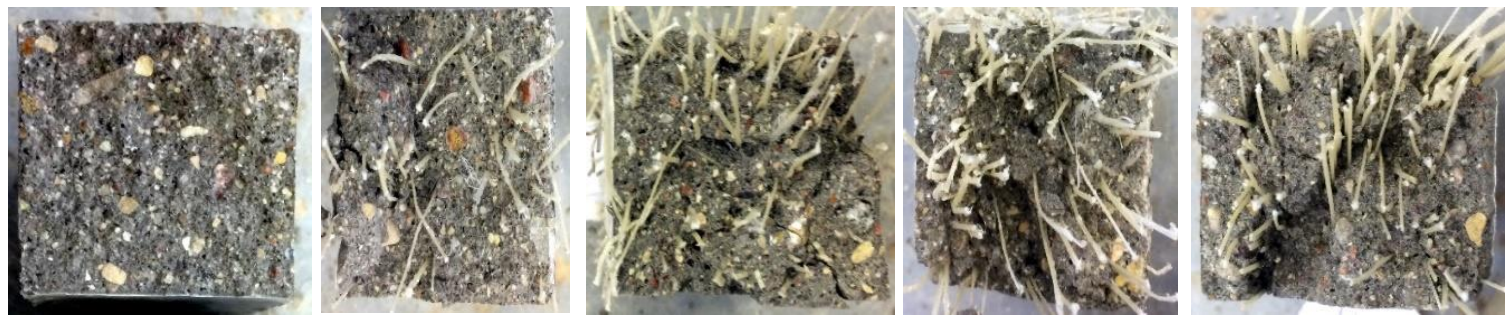

Figure 13. Cross section of concrete samples.

\section{Conclusions}

This study showed that polyolefin fibers are suitable for construction, where higher bending strength is required. It showed that the without-fiber-content sample, S-1, had 74.8 MPa of compressive strength and $8.1 \mathrm{MPa}$ bending strength on the 28th day destructive test. Sample S-2 achieved higher compressive strength on the 7th day compressive test, than any of the other samples. Whereas on the 28 th day compressive test, sample S-1 achieved highest compressive strength. And from the study, we showed that the compressive strength of concrete samples were decreasing with respect to the addition of high amounts of polyolefin fibers. And in terms of bending strength, sample S-2 achieved higher bending strength than any other sample on the 28th day. Where sample S-3 achieved higher bending strength in the early stage (on the 7th day). So, from this study we showed that sample S-2 had better results in terms of bending strength, while in the other samples, the bending strength started decreasing with addition of fiber quantity.

From this study, we can conclude sample S-2 had higher results in case of bending strength, while compromising only a small amount of compressive strength. Polyolefin macro fibers had good results on post-cracking behavior. After the failure of concrete specimen by three-point bending test, all the fiber content specimens were not fully separated because of the fiber content. Sample S-2 can be used in the construction sector where high bending strength is required. Polyolefin fiber concrete is also cost efficient and very useful. I hope future studies will be done to gain higher compressive strength along with higher bending strength with addition of polyolefin macro-fibers.

Author Contributions: This paper consists combination effort of two authors S.K.A. and Z.R. Preparing samples, carrying out the experiments, analyzing data and drafting manuscript were done jointly.

Acknowledgments: All the material and test support received from Faculty of Civil Engineering and Architecture, Kaunas University of Technology, Kaunas LT-44249, Lithuania. We are gratefully acknowledged their support for their contribution and help.

Conflicts of Interest: The authors declare no conflicts of interest.

\section{References}

1. Yao, W.; Li, J.; Wu, K. Mechanical properties of hybrid fiber-reinforced concrete at low fiber volume fraction. Cem. Concr. Res. 2003, 33, 27-30. [CrossRef]

2. Rousakis, T.C.; Tourtouras, I.S. Modeling of passive and active external confinement of RC columns with elastic material. ZAMM-J. Appl. Math. Mech./Z. Angew. Math. Mech. 2015, 95, 1046-1057. [CrossRef] 
3. Hannawi, K.; Bian, H.; Prince-Agbodjan, W.; Raghavan, B. Effect of different types of fibers on the microstructure and the mechanical behavior of Ultra-High-Performance Fiber Reinforced Concretes. Compos. Part B-Eng. 2016, 86, 214-220. [CrossRef]

4. Zhang, P.; Li, Q.F. Effect of polypropylene fiber on durability of concrete composite containing fly ash and silica fume. Compos. Part B-Eng. 2013, 45, 1587-1594. [CrossRef]

5. Husem, M. The effects of high temperature on compressive and flexural strengths of ordinary and high-performance concrete. Fire Saf. J. 2006, 41, 155-163. [CrossRef]

6. Pakravan, H.R.; Latifi, M.; Jamshidi, M. Hybrid short fiber reinforcement system in concrete: A review. Constr. Build. Mater. 2017, 142, 280-294. [CrossRef]

7. EN 14889-2. Fibres for Concrete. Polymer Fibres. Definitions, Specifications and Conformity; Czech Office for Standards, Metrology and Testing: Prague, Czech, 2008.

8. Alberti, M.G.; Enfedaque, A.; Gálvez, J.C.; Agrawal, V. Reliability of polyolefin fibre reinforced concrete beyond laboratory sizes and construction procedures. Compos. Struct. 2016, 140, 506-524. [CrossRef]

9. Banthia, N.; Gupta, P.; Yan, C.; Morgan, D.R. How tough is fiber reinforced shotcrete? Part 1. Beam tests. Concr. Int. 1999, 21, 59-62.

10. Ugbolue, S.C. Polyolefin Fibers: Industrial and Medical Applications; CRC Press: Cambridge, UK, 2009.

11. Pyle, R.W. Product and Method for Incorporating Synthetic Polymer Fibers into Cement Mixtures. U.S. Patent 6,258,159, 10 July 2001.

12. Islam, G.S.; Gupta, S.D. Evaluating plastic shrinkage and permeability of polyolefin fibber reinforced concrete. Int. J. Sustain. Built Environ. 2016, 5, 345-354. [CrossRef]

13. Saghi, H.; Delbari, H. The effect of the polyolefin fibers and concrete strength on polyolefin shrinkage cracking in concrete slabs. J. Concr. Res. 2015, 8, 35-46.

14. Pujadas, P.; Blanco, A.; Cavalaro, S.H.; De la Fuente, A.; Aguado, A. Flat Suspended Slabs Reinforced only with Macro-Synthetic Fibres. In Proceedings of the 9th RILEM International Symposium on Fiber Reinforced Concrete (BEFIB 2016), Vancouver, BC, Canada, 19-21 September 2016; pp. 1300-1308.

15. Liu, X.; Huang, Y.; Deng, C.; Wang, X.; Tong, W.; Liu, Y.; Huang, J.; Yang, Q.; Liao, X.; Li, G. Study on the Creep Behavior of Polypropylene Xiaolin. Polym. Eng. Sci. 2009, 49, 1375-1382. [CrossRef]

16. Pujadas, P.; Blanco, A.; Cavalaro, S.H.; de la Fuente, A.; Aguado, A. Flexural Post-Cracking Creep Behaviour of Macro-Synthetic and Steel Fiber Reinforced Concrete. In Creep Behaviour in Cracked Sections of Fibre Reinforced Concrete, Proceedings of the International RILEM Workshop FRC-CREEP 2016; Serna, P., LlanoTorre, A., Cavalaro, S.H.P., Eds.; Springer: New York, NY, USA, 2016; pp. 77-87.

17. Gowri, T.V.; Sravana, P.; Rao, P.S. On the Relationship between Compressive Strength and Water Binder Ratio of High Volumes of Slag Concrete. Int. J. Appl. Eng. Res. 2016, 11, 1436-1442.

18. Rahmani, K.; Shamsai, A.; Saghafian, B.; Peroti, S. Effect of Water and Cement Ratio on Compressive Strength and Abrasion of Microsilica Concrete. Middle-East J. Sci. Res. 2012, 12, 1056-1061.

19. Apebo, N.S.; Shiwua, A.J.; Agbo, A.P.; Ezeokonkwo, J.C.; Adeke, P.T. Effect of Water-Cement Ratio on the Compressive Strength of gravel-crushed over burnt bricks concrete. Civ. Environ. Res. 2013, 3, 74-80.

(C) 2018 by the authors. Licensee MDPI, Basel, Switzerland. This article is an open access article distributed under the terms and conditions of the Creative Commons Attribution (CC BY) license (http:// creativecommons.org/licenses/by/4.0/). 